\title{
Film growth precursors in a remote SiH/sub 4/ plasma used for high-rate deposition of hydrogenated amorphous silicon
}

Citation for published version (APA):

Kessels, W. M. M., Sanden, van de, M. C. M., \& Schram, D. C. (2000). Film growth precursors in a remote $\mathrm{SiH} / \mathrm{sub}$ 4/ plasma used for high-rate deposition of hydrogenated amorphous silicon. Journal of Vacuum Science and Technology A: Vacuum, Surfaces, and Films, 18(5), 2153-2163. https://doi.org/10.1116/1.1289541

DOI:

10.1116/1.1289541

Document status and date:

Published: 01/01/2000

\section{Document Version:}

Publisher's PDF, also known as Version of Record (includes final page, issue and volume numbers)

\section{Please check the document version of this publication:}

- A submitted manuscript is the version of the article upon submission and before peer-review. There can be important differences between the submitted version and the official published version of record. People interested in the research are advised to contact the author for the final version of the publication, or visit the $\mathrm{DOI}$ to the publisher's website.

- The final author version and the galley proof are versions of the publication after peer review.

- The final published version features the final layout of the paper including the volume, issue and page numbers.

Link to publication

\section{General rights}

Copyright and moral rights for the publications made accessible in the public portal are retained by the authors and/or other copyright owners and it is a condition of accessing publications that users recognise and abide by the legal requirements associated with these rights.

- Users may download and print one copy of any publication from the public portal for the purpose of private study or research.

- You may not further distribute the material or use it for any profit-making activity or commercial gain

- You may freely distribute the URL identifying the publication in the public portal.

If the publication is distributed under the terms of Article 25fa of the Dutch Copyright Act, indicated by the "Taverne" license above, please follow below link for the End User Agreement:

www.tue.nl/taverne

Take down policy

If you believe that this document breaches copyright please contact us at:

openaccess@tue.nl

providing details and we will investigate your claim. 


\title{
Film growth precursors in a remote $\mathrm{SiH}_{4}$ plasma used for high-rate deposition of hydrogenated amorphous silicon
}

\author{
W. M. M. Kessels, ${ }^{a}$ M. C. M. van de Sanden, ${ }^{\text {b) }}$ and D. C. Schram \\ Department of Applied Physics, Eindhoven University of Technology, P.O. Box 513, 5600 MB Eindhoven, \\ The Netherlands
}

(Received 10 December 1999; accepted 26 June 2000)

\begin{abstract}
The $\mathrm{SiH}_{4}$ dissociation products and their contribution to hydrogenated amorphous silicon $(a-\mathrm{Si}: \mathrm{H})$ film growth have been investigated in a remote $\mathrm{Ar}-\mathrm{H}_{2}-\mathrm{SiH}_{4}$ plasma which is capable of depositing device-quality $a$ - $\mathrm{Si}: \mathrm{H}$ at $10 \mathrm{~nm} / \mathrm{s}$. $\mathrm{SiH}_{3}$ radicals have been detected by means of threshold ionization mass spectrometry for different fractions of $\mathrm{H}_{2}$ in the $\mathrm{Ar}-\mathrm{H}_{2}$-operated plasma source. It is shown that at high- $\mathrm{H}_{2}$ flows, $\mathrm{SiH}_{4}$ dissociation is dominated by hydrogen abstraction and that $\mathrm{SiH}_{3}$ contributes dominantly to film growth. At low- $\mathrm{H}_{2}$ flows, a significant amount of very reactive silane radicals, $\mathrm{SiH}_{x}(x \leqslant 2)$, is produced, as concluded from threshold ionization mass spectrometry on $\mathrm{SiH}_{2}$ and optical emission spectroscopy on excited $\mathrm{SiH}$ and $\mathrm{Si}$. These radicals are created by dissociative recombination reactions of silane ions with electrons and they, or their products after reacting with $\mathrm{SiH}_{4}$, make a large contribution to film growth at low- $\mathrm{H}_{2}$ flows. This is corroborated by the overall surface reaction probability which decreases from $\sim 0.5$ to $\sim 0.3$ with increasing $\mathrm{H}_{2}$ fraction. The film properties improve with increasing $\mathrm{H}_{2}$ flow and device-quality $a$-Si:H is obtained at high $\mathrm{H}_{2}$ fractions where $\mathrm{SiH}_{3}$ dominates film growth. Furthermore, it is shown that at high- $\mathrm{H}_{2}$ flows the contribution of $\mathrm{SiH}_{3}$ is independent of the $\mathrm{SiH}_{4}$ flow while the deposition rate varies over one order of magnitude. (C) 2000 American Vacuum Society. [S0734-2101(00)08005-2]
\end{abstract}

\section{INTRODUCTION}

The increasing demand for clean energy sources has initiated a lot of research on hydrogenated amorphous-silicon $(a-\mathrm{Si}: \mathrm{H})$ and its application in thin-film solar cells. To increase their competitiveness with conventional energy sources, the work in this field is mainly focused on increasing the solar cells' (stable) efficiency, the application of new low-cost materials, and the improvement of the production processes, which should all be compatible with large-area deposition and a high throughput. In this respect, one of the central questions is whether it is possible to deposit $a-\mathrm{Si}: \mathrm{H}$ suitable for the application in thin solar cells at high growth rates (preferably $>1 \mathrm{~nm} / \mathrm{s}$ ). Several investigations have already addressed this question, ${ }^{1-10}$ and recently it was shown that device-quality $a-\mathrm{Si}: \mathrm{H}$ can be obtained even at a rate of $10 \mathrm{~nm} / \mathrm{s}$ with the expanding thermal plasma. ${ }^{11,12}$ This technique combines a high-pressure thermal plasma source with a low-pressure deposition chamber and is, therefore, a real remote plasma. The $a$-Si:H obtained has some remarkable properties, such as an enhanced hole drift mobility, and the good film quality is confirmed by the results on the first, not yet optimized, solar cells which contained intrinsic $a-\mathrm{Si}: \mathrm{H}$ deposited at a rate of $7 \mathrm{~nm} / \mathrm{s} .{ }^{11,12}$

To have insight into the conditions under which goodquality $a-\mathrm{Si}: \mathrm{H}$ can be obtained at high-deposition rates and what are the limitations, the reactions in the plasma and at the film surface are studied for the expanding thermal plasma. It yields a better understanding of the deposition process of $a-\mathrm{Si}: \mathrm{H}$ and the resulting film properties, which enables further process and film quality optimization. This

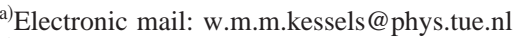

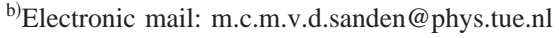

knowledge is also of importance for other (low-deposition rate) $\mathrm{SiH}_{4}$ plasmas, and it can yield insight into how to increase the growth rate in these plasmas while maintaining good film quality.

This article, which is part of a project aiming at a good understanding of the plasma processes and film growth in the expanding thermal plasma, deals with the plasma chemistry which has already been addressed globally in previous work. ${ }^{13}$ Here, the dissociation reactions of $\mathrm{SiH}_{4}$ are considered in more detail and information on the contribution of the specific reaction products to film growth is obtained from applying several plasma diagnostics. This is done for different plasma conditions and the results are related to the obtained film properties, which are presented in detail in another article. ${ }^{14}$ It is focused on the silane radicals $\left(\mathrm{SiH}_{x}, x\right.$ $\leqslant 3$ ) because an extensive investigation of the ion chemistry showed that the contribution of $\mathrm{Si}_{n} \mathrm{H}_{m}^{+}$ions is less than $10 \%$, in terms of $\mathrm{Si}$ atoms deposited, for all conditions. ${ }^{15,16}$ The contribution of the different radicals is expected to have important implications for the film quality because the film properties are strongly dependent on the plasma parameters while the contribution of the ions remains about constant. The radicals are studied by a combination of diagnostics, such as threshold ionization mass spectrometry, optical emission spectroscopy, and aperture-well experiments, which have been applied to two parameter studies: the variation of the plasma source operation by changing the $\mathrm{H}_{2}$ flow in the source and the variation of the downstream $\mathrm{SiH}_{4}$ density.

\section{EXPERIMENT}

\section{A. Deposition setup and plasma source operation}

The deposition setup is depicted schematically in Fig. 1 and it consists of a cascaded arc plasma source and a depo- 
(a)

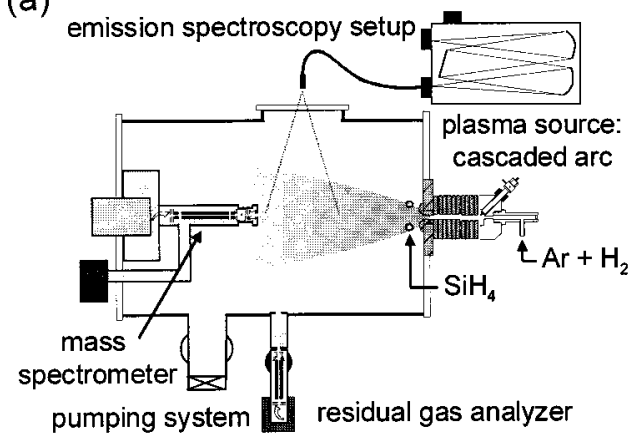

(b)

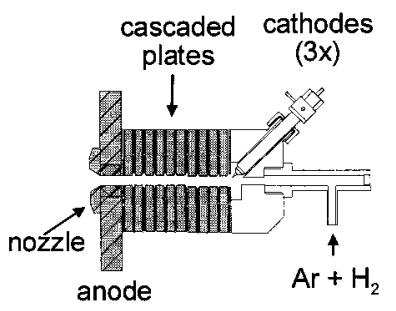

FIG. 1. (a) Schematic of the expanding thermal plasma and plasma diagnostics. The mass spectrometer is located at the usual position of the substrate holder. (b) The cascaded arc plasma source. sition chamber. In the latter, $\mathrm{SiH}_{4}$ is injected where it is dissociated by the reactive species emanating from the $\mathrm{Ar}-\mathrm{H}_{2}$-operated plasma source. The deposition setup and cascaded arc are described in detail in Refs. 16 and 17, respectively, and the conditions for the plasmas studied in this article are listed in Table I. Here, only the characteristics of the plasma emanating from the plasma source will be described briefly for its different operation conditions and some striking differences between the expanding thermal plasma and conventional deposition plasmas will be given.

The cascaded arc is a thermal plasma source and it is operated on a mixture of $\mathrm{Ar}$ and $\mathrm{H}_{2}$, at high pressure and high gas flows [expressed in standard cubic centimeters per second (sccs)]. In the source, there is typically an electron density $n_{e}=\sim 10^{22} \mathrm{~m}^{-3}$ and an electron and heavy-particle temperature $T_{e}=T_{h}=\sim 1 \mathrm{eV} .{ }^{17}$ The pressure in the deposition chamber is kept low $(\sim 0.20$ mbar $)$ by means of roots blowers with a high pumping capacity. Therefore, the plasma expands from the cascaded arc into the deposition chamber. Operated on pure Ar, the downstream plasma has a high electron density and relatively low electron temperature: both Thomson-scattering experiments as well as Langmuirprobe measurements have revealed $n_{e}=\sim 10^{19} \mathrm{~m}^{-3}$ and $T_{e}$ $=\sim 0.3 \mathrm{eV}$ for the presented conditions. ${ }^{16,18}$ The dissociation of $\mathrm{SiH}_{4}$ by electron processes is, therefore, negligible in comparison with dissociation reactions by reactive ionic and atomic particles. When the source is operated on pure Ar this is mainly by $\mathrm{Ar}^{+}$.

When $\mathrm{H}_{2}$ is admixed to the $\mathrm{Ar}$ in the arc, $n_{e}$ in the downstream region is drastically reduced (a factor of 40 going from 0 to $10 \operatorname{sccs} \mathrm{H}_{2}$ ) due to associative charge transfer reactions between $\mathrm{Ar}^{+}$and $\mathrm{H}_{2}$ followed by dissociative recombination with electrons. ${ }^{13,16,19,20} T_{e}$ decreases to $0.1-0.2$

TABLE I. Setup conditions of the expanding thermal plasma for high-rate deposition of $a-\mathrm{Si}: \mathrm{H}$.

\begin{tabular}{ll}
\hline \hline Ar flow & $55 \mathrm{sccs}$ \\
$\mathrm{H}_{2}$ flow & $0-15 \mathrm{sccs}$ \\
Arc current & $45 \mathrm{~A}$ \\
Arc voltage & $70-140 \mathrm{~V}$ \\
Arc pressure & $\sim 400 \mathrm{mbar}$ \\
$\mathrm{SiH}_{4}$ flow & $1-20 \mathrm{sccs}$ \\
Downstream pressure & $0.18-0.20 \mathrm{mbar}$ \\
\hline
\end{tabular}

$\mathrm{eV}$ (Refs. 16 and 20) and the dominant ion in the downstream region changes to $\mathrm{H}^{+} .{ }^{16}$ Furthermore, the $\mathrm{H}_{2}$ in the cascaded arc is effectively dissociated due to the high gas temperature $(\sim 1 \mathrm{eV})$ in the plasma source..$^{21}$ Consequently, for a considerable fraction of $\mathrm{H}_{2}$, the cascaded arc acts predominantly as an atomic hydrogen source.

For different $\mathrm{H}_{2}$ fractions, the total ion flow emanating from the arc has been determined by radial Langmuir-probe measurements just after the arc exit. It revealed an ion fluence of almost $3 \mathrm{sccs}$ for a pure Ar plasma and $0.07 \mathrm{sccs}$ for a plasma with $10 \operatorname{sccs~} \mathrm{H}_{2} \cdot{ }^{13,16}$ The amount of $\mathrm{H}$ in the downstream region has been quantified by means of two-photonabsorption laser-induced fluorescence (TALIF) under similar conditions in a different reactor. ${ }^{22}$ The determination of the total fluence of $\mathrm{H}$ available for $\mathrm{SiH}_{4}$ dissociation from these measurements is more complicated. Although it is expected that the $\mathrm{H}_{2}$ in the cascaded arc is nearly fully dissociated, it has been shown that a significant amount of $\mathrm{H}$ is lost by recombination in the nozzle of the plasma source and by fast radial escape of $\mathrm{H}$ from the shock. The forward flow of $\mathrm{H}$ has been estimated at roughly 1-2 sccs for an injected $\mathrm{H}_{2}$ flow of 10 sccs. $^{22}$

Apart from the fact that $\mathrm{SiH}_{4}$ is not dissociated by electrons, other important differences with conventional plasma deposition techniques are the low energy that ions gain in the plasma sheath $(\sim 1-2 \mathrm{eV})$ and the relatively high gas temperature [1000-1500 K (Refs. 23 and 24)]. The low ion energy is a consequence of the low $T_{e}$ and it saves the deposited films from severe ion bombardment (additional ion energy can be obtained by applying an external rf bias on the substrate). The high gas temperature is due to the fact that the plasma is thermal in origin.

\section{B. Threshold ionization mass spectrometry}

The substrate holder has been replaced by a mass spectrometer (see Fig. 1) to analyze the flux of radicals towards the substrate. The mass spectrometer, with a similar geometry as the substrate holder, is a modified version (PSM Upgrade) of the Hiden Analytical EPIC 300, which suffered from detection of plasma photons because its detector was in direct line of sight with the plasma source. ${ }^{16}$ In the upgrade, the detector is blocked from photons from the source by adding a Bessel-box type of energy analyzer. Gas extraction 
takes place by a knife-edged extraction orifice with a diameter and thickness of $50 \mu \mathrm{m}$. This leads to an effusive flow of the plasma species in the mass spectrometer, which is differentially pumped by a $56 \mathrm{l} / \mathrm{s}$ turbopump. During plasma operation with a typical pressure of $0.20 \mathrm{mbar}$, the pressure in the mass spectrometer is within the range $7 \times 10^{-7}$ $-10^{-6}$ mbar. The ionizer region with the filament is located at about $24 \mathrm{~mm}$ from the extraction orifice. The linear filament is made of thoriated iridium and yields a high electron emission current $I_{e}$ at relatively low temperatures: $I_{e}$ is actively controlled at $50 \mu \mathrm{A}$, corresponding with a filament temperature of about $1800 \mathrm{~K}$. Behind the ionizer the Bessel box is located, which is followed by the mass filter (with rf-driven pre- and postfilter) and channeltron (DeTech 415).

To distinguish ionization of radicals in the mass spectrometer from dissociative ionization of $\mathrm{SiH}_{4}$ the threshold ionization or appearance potential method has been used. This method is described in detail in the literature..$^{25,26}$ Briefly, the energy of the electrons emitted by the filament is scanned in the vicinity of the ionization potential of the radical of interest, while monitoring the intensity at its massover-charge ratio. At electron energies $E$ higher than the ionization potential $E_{i}$ of the radical but lower than the potential for dissociative ionization of the parent molecule into the specific ionic channel (appearance potential $E_{a}$ ), the measured intensity $I(E)$ is a measure for the radical density $n$ in the plasma:

$$
I(E)=\alpha I_{e} \sigma(E) n, \quad \text { with } E_{i}<E<E_{a},
$$

with $\sigma(E)$ the cross section for ionization and $\alpha$ a geometry and mass-dependent proportionality constant. The measured radical intensity is corrected for the contribution by pyrolysis, i.e., thermal decomposition, of $\mathrm{SiH}_{4}$ on the filament by subtracting the signal at $E<E_{a}$ obtained for the "plasma off" condition. Herein, differences in the $\mathrm{SiH}_{4}$ signal at $E$ $\gg E_{a}$ during "plasma on" and "plasma off" (due to $\mathrm{SiH}_{4}$ consumption and/or gas temperature effects) are taken into account. $^{27}$

Quantification of the radical density takes place by linking the radical intensity to the measured intensity of the parent $\mathrm{SiH}_{4}$ molecule at $E \gg E_{a} \cdot{ }^{25,26}$ The latter can directly be related to the known partial pressure of $\mathrm{SiH}_{4}$ during "plasma off." In this method, besides the difference in cross sections for electron-induced ionization of the radical and parent molecule (at the appropriate electron energies), also the difference in surface reactivity should be taken into account. $\mathrm{SiH}_{4}$ is not reactive and will lead to a residual partial pressure in the mass spectrometer, whereas silane radicals are rather reactive ${ }^{28}$ and are easily lost on their way to and in the ionizer. Therefore, practically only $\mathrm{SiH}_{\mathrm{x}}$ radicals in the beam of the effusive flux that reaches the ionizer without wall collisions (determined by the acceptance angle) contribute to the $\mathrm{SiH}_{\mathrm{x}}$ intensity (beam component), whereas the measured intensity for $\mathrm{SiH}_{4}$ has both a beam and residual density component. This difference can be taken into account by a correction factor $C$ that can be estimated from the density $n_{\text {beam }}$ of $\mathrm{SiH}_{4}$ in the beam originating directly from the extraction orifice and the density $n_{\text {res }}$ of residual $\mathrm{SiH}_{4}$ at the position of the ionizer:

$$
C=\frac{n_{\text {beam }}+n_{\text {res }}}{n_{\text {beam }}} .
$$

For a $\mathrm{SiH}_{4}$ density $n$ and a thermal velocity $v$ in front of the extraction orifice with area $A$, these densities in the ionizer at a position $l$ from the extraction orifice are given by ${ }^{29}$

$$
n_{\text {beam }}=\frac{n A}{4 \pi l^{2}} \quad \text { and } \quad n_{\text {res }}=\frac{\frac{1}{4} n v A}{S},
$$

where $S$ is the pumping speed for $\mathrm{SiH}_{4}$ at the position of the ionizer. For the present setup, this yields $C \approx 35$ when using $S=561 / \mathrm{s}$. This high value of $C$ means that the residual $\mathrm{SiH}_{4}$ density in the ionizer is much higher than the density of $\mathrm{SiH}_{4}$ in the beam directly originating from the extraction orifice. The residual gas density in the ionizer can be reduced by applying double partial pumping as done by Kae-Nune et al. ${ }^{26}$ Furthermore, our case differs from the one described by Singh, Coburn, and Graves ${ }^{30}$ by the fact that for silane radicals the surface loss probability is much higher than for the radicals studied in their work.

In this procedure it is important that the emission current $I_{e}$ is independent of electron energy $E$. This requires that $I_{e}$ is controlled at rather low currents because at higher currents space charge can easily build up around the filament for low- $E$ values, as described by the Child-Langmuir law. This can cause $I_{e}$ to deviate considerably from the demanded $I_{e}$ and to depend on $E$. This effect has experimentally been investigated yielding that for $I_{e}=50 \mu \mathrm{A}$ the influence of space charge is negligible down to $E=5 \mathrm{eV}$.

Furthermore, space-charge effects, as well as the thermal energy distribution of emitted electrons, the potential drop along the filament, and contact and surface potentials of the electrodes, lead also to an electron energy which is not purely monoenergetic. This causes an apparent onset of the signal below the ionization potential and troubles the determination of the ionization potential and/or calibration of the electron energy scale. For the Hiden system the half width at half maximum value is estimated to be within $0.5 \mathrm{eV}$. The electron energy scale has been calibrated by means of the ionization potential of noble gases and applying the commonly used linear extrapolation method. ${ }^{31}$ This revealed that the electron energies are $\sim 1.4 \mathrm{eV}$ lower than indicated by the energy scale.

\section{Emission spectroscopy}

Emission spectroscopy has been applied to monitor the emission by excited $\mathrm{SiH}$ and $\mathrm{Si}$ radicals. For $\mathrm{SiH}$ the $A^{2} \Delta-X^{2} \Pi$ electronic transition band at around $414 \mathrm{~nm}$ has been analyzed and for $\mathrm{Si}$ I the $4 s^{1} P^{0}-3 p^{21} S$ transition at $390.6 \mathrm{~nm}$. The emission spectroscopy setup is a modified version of the one described in Ref. 32, which dealt with measurements under less relevant plasma conditions in terms of resulting $a$-Si:H quality. By means of a high-grade fused- 
silica fiber (Oriel 77532), the total (i.e., nonlocal) emission by the plasma in the region from the substrate to $\sim 20 \mathrm{~cm}$ upstream has been collected and focused on a CzernyTurner monochromator (Jobin-Yvon HR 640) with a focal length of $640 \mathrm{~mm}$ and a dispersion of $1 \mathrm{~nm} / \mathrm{mm}$. The entrance slit used is $250 \mu \mathrm{m}$ and a charge-coupled-device camera (SBIG ST-6 Optohead), recording a wavelength range of $\sim 11 \mathrm{~nm}$, has been used as the detector.

Emission by $\mathrm{Ar}$ in a pure Ar plasma is used as a reference to correct for reduced transmission due to deposition on the spectroscopic window. Furthermore, the integration time is chosen such that the correction for this reduced transmission is rather constant for the different plasma conditions. Moreover, the reactor is cleaned by means of an $\mathrm{Ar}-\mathrm{CF}_{4}$ plasma after every measurement.

Only nonlocal and relative measurements of the emission intensity have been performed, and from fitting simulations of the $\mathrm{SiH}$ emission spectrum to the experimental data the vibrational and rotational temperatures of the excited radical have been extracted. This technique, explored by Perrin and Delafosse, ${ }^{33}$ is applied by using an improved version of the program described in Ref. 32.

\section{Other diagnostics}

The other diagnostics will be presented only briefly as they are described extensively in previous articles. The depletion or net consumption of $\mathrm{SiH}_{4}$ for the different plasma conditions has been determined by a residual gas analyzer (Balzers Prisma QMS 200) located at the side of the deposition chamber. The difference in the measured signal $I$ due to $\mathrm{SiH}_{4}($ at $m / e=28-32)$ when the plasma is on and off can be attributed completely to the consumption of $\mathrm{SiH}_{4} \cdot{ }^{13}$ The equivalent flow of $\mathrm{SiH}_{4}$ that is consumed by the plasma $\Phi_{\mathrm{SiH}_{4} \text {,cons }}$, is calculated by multiplying the fraction of $\mathrm{SiH}_{4}$ that is consumed with the initial $\mathrm{SiH}_{4}$ flow $\Phi_{\mathrm{SiH}_{4}}$ :

$$
\Phi_{\mathrm{SiH}_{4}, \text { cons }}=\left(\frac{I_{\text {off }}-I_{\text {on }}}{I_{\text {off }}}\right) \Phi_{\mathrm{SiH}_{4}} .
$$

The overall surface reaction probability of the species contributing to growth has been determined from so-called "aperture-well" experiments. ${ }^{28,34}$ This technique uses a well, created by two substrates, in which reactive particles from the plasma entering through a small slit in the upper substrate are trapped. From the distribution of amount of film deposited on both substrates an overall surface reaction probability $\beta_{0}$ can be calculated, which depends on the relative fluxes of the reactive species entering the well and their particular surface reaction probability $\beta$. More information can be found in Ref. 28.

\section{RESULTS}

\section{A. $\mathrm{H}_{2}$ flow series}

In this section, the dissociation of $\mathrm{SiH}_{4}$ is considered for different operating regimes of the cascaded arc as presented in Sec. II A. The $\mathrm{SiH}_{4}$ flow is kept fixed at 10 sccs. The net consumed $\mathrm{SiH}_{4}$ flow is given in Fig. 2 as a function of the $\mathrm{H}_{2}$

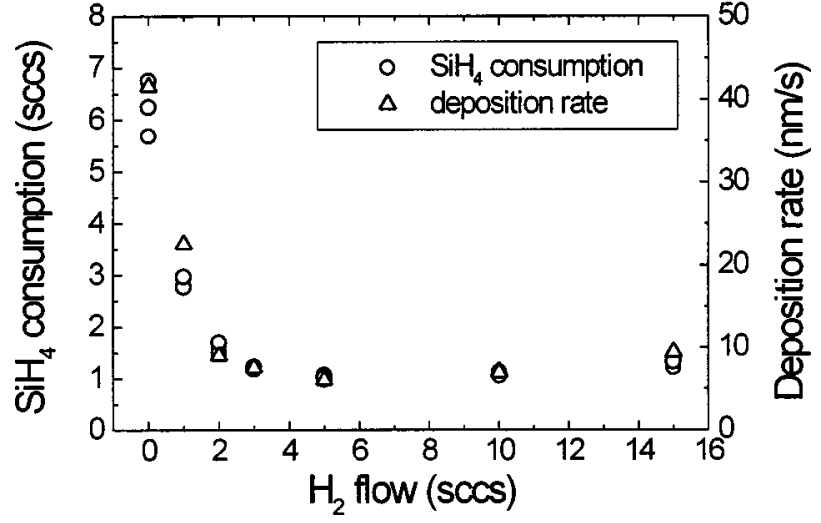

FIG. 2. Consumption of $\mathrm{SiH}_{4}$ expressed in equivalent flow as a function of $\mathrm{H}_{2}$ admixture in the cascaded arc. The $\mathrm{SiH}_{4}$ flow is $10 \mathrm{sccs}$. The corresponding deposition rate for a substrate temperature of $400{ }^{\circ} \mathrm{C}$ is given on the right axis.

flow in the cascaded arc. For zero $\mathrm{H}_{2}$ flow, the $\mathrm{SiH}_{4}$ consumption is very large $(\sim 60 \%)$. This can be attributed to ion-induced reactions as mainly $\mathrm{Ar}^{+}$emanates from the plasma source. For increasing the $\mathrm{H}_{2}$ admixture the $\mathrm{SiH}_{4}$ consumption first decreases due to decreasing ion fluence while for $\mathrm{H}_{2}$ flows $>3 \mathrm{sccs}$ the reactions with $\mathrm{H}$ take over. From that point, the $\mathrm{SiH}_{4}$ consumption increases slightly due to an increasing $\mathrm{H}$ flow from the arc. Apparently, the consumption of $\mathrm{SiH}_{4}$ for the H-dominated region is lower than for the ion-dominated region. In Fig. 2, also the corresponding deposition rate for a substrate temperature of $400^{\circ} \mathrm{C}$ is given. From the fact that the deposition rate (when corrected for the $\mathrm{Si}$ atomic film density) scales very well with the consumption of $\mathrm{SiH}_{4}$, it can be concluded that the consumed $\mathrm{SiH}_{4}$ is mostly converted into $a-\mathrm{Si}: \mathrm{H}$ and not into polysilanes, as also corroborated by the small fraction of $\mathrm{Si}_{2} \mathrm{H}_{6}$ and $\mathrm{Si}_{3} \mathrm{H}_{8}$ observed. ${ }^{13,16}$

At high- $\mathrm{H}_{2}$ flows, it is expected that mainly $\mathrm{SiH}_{3}$ will be created as the reaction of $\mathrm{H}$ with $\mathrm{SiH}_{4}$ leads to hydrogen abstraction of $\mathrm{SiH}_{4}$ :

$$
\mathrm{H}+\mathrm{SiH}_{4} \rightarrow \mathrm{SiH}_{3}+\mathrm{H}_{2} .
$$

The rate of this reaction is given by $1.8 \times 10^{-16}$ $\times \exp (-1925 / T) \mathrm{m}^{3} \mathrm{~s}^{-1}$ for a gas temperature $T$ (in K) in the range $290-660 \mathrm{~K}$, while at higher temperatures rates higher than predicted from this relation have been proposed. ${ }^{35}$ Therefore, $\mathrm{SiH}_{3}$ has been measured by threshold ionization mass spectrometry. An electron energy scan at $m / e=31$ corresponding with the $\mathrm{SiH}_{3}{ }^{+}$ion is given in Fig. 3. The used integration time per step in $E$ is $1.5 \mathrm{~s}$. At low values of $E$ a hump due to direct ionization of $\mathrm{SiH}_{3}$ can clearly be seen, while at higher energies the signal due to dissociative ionization of $\mathrm{SiH}_{4}$ comes up. The depicted electron energy scale is not rescaled, and the too high ionization and appearance potential of $\mathrm{SiH}_{3}$ and $\mathrm{SiH}_{4}$ are in fair agreement with the shift of $+1.4 \mathrm{eV}$ obtained from the calibration procedure. For high $E$, the signal for "plasma on" is normalized to the one 


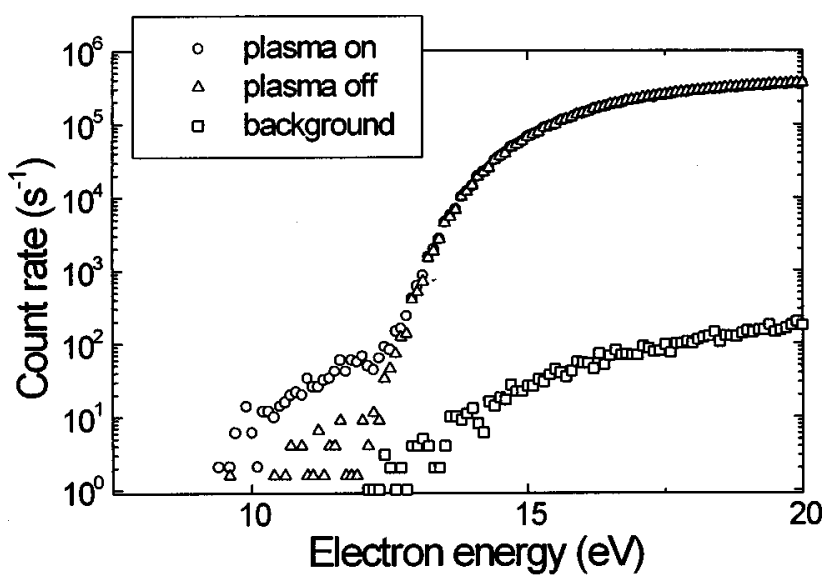

FIG. 3. Electron energy scan at $m / e=31$ for determination of the $\mathrm{SiH}_{3}$ density. The values for "plasma off" are normalized to those of "plasma on" at high electron energies. Both the $\mathrm{H}_{2}$ and $\mathrm{SiH}_{4}$ flows are 10 sccs. The background signal, obtained with $\mathrm{SiH}_{4}$ flow $=0$ sccs, is due to an (unknown) contaminant in the mass spectrometer.

for "plasma off"' such that the signal for "plasma off" due to pyrolysis (at $E<E_{a}$ ) can be subtracted directly from the radical signal.

The densities of $\mathrm{SiH}_{3}$ obtained for different $\mathrm{H}_{2}$ flows in the arc are given in Fig. 4(a). A complication arises from the fact that the gas extraction orifice becomes easily clogged due to the high-deposition rate. This is (partly) circumvented by monitoring a reference signal, but especially the $\mathrm{SiH}_{3}$ measurements at very low $\mathrm{H}_{2}$ flows, with deposition rates up to $60 \mathrm{~nm} / \mathrm{s}$, were cumbersome. The absolute values of the $\mathrm{SiH}_{3}$ densities have been estimated by the method described in Sec. IIB. The partial ionization cross sections of $\mathrm{SiH}_{4}$ have been taken from Ref. 36. Information about ionization cross sections for $\mathrm{SiH}_{x}$ radicals has been only recently available from work by Tarnovsky, Deutsch, and Becker who determined ionization cross sections for $\mathrm{SiD}_{x}$ radicals. ${ }^{37}$ The latter cross sections for $\mathrm{SiD}_{3}$ and $\mathrm{SiD}_{2}$ radicals at $E=10 \mathrm{eV}$ are, respectively, a factor of $\sim 4$ smaller and $\sim 2$ larger than those estimated by Kae-Nune et al. ${ }^{26}$ from ionization cross sections of $\mathrm{CD}_{x}$ radicals. ${ }^{38,39}$ We note that the absolute scale of the $\mathrm{SiH}_{3}$ density in Fig. 4(a) has a considerable uncertainty, mainly due to the uncertainty of $S$ (and, consequently, C) for $\mathrm{SiH}_{4}$ at the position of the ionizer.

The $\mathrm{SiH}_{3}$ density shows a steep decrease going from zero to a small $\mathrm{H}_{2}$ flow, followed by a gradual increase for higher flows. The latter is in agreement with an increasing flow of $\mathrm{H}$ from the cascaded arc. For the interpretation of the $\mathrm{SiH}_{3}$ density at low- $\mathrm{H}_{2}$ flows, it is important to realize that at these flows much more $\mathrm{SiH}_{4}$ is consumed. The $\mathrm{SiH}_{3}$ density at 0 sccs $\mathrm{H}_{2}$ is about equal to the one at $15 \mathrm{sccs} \mathrm{H}_{2}$, yet the net consumed $\mathrm{SiH}_{4}$ flow is at least a factor of 4 higher. It is, therefore, better to consider the contribution of $\mathrm{SiH}_{3}$ to film growth. Determination of the absolute value of the contribution from the densities ${ }^{26}$ in Fig. 4(a) is, however, cumbersome. First, there are uncertainties in the absolute density itself. Second, estimations on the thermal velocity $v$ and sticking probability $s$ of $\mathrm{SiH}_{3}$ are required, where especially $s$
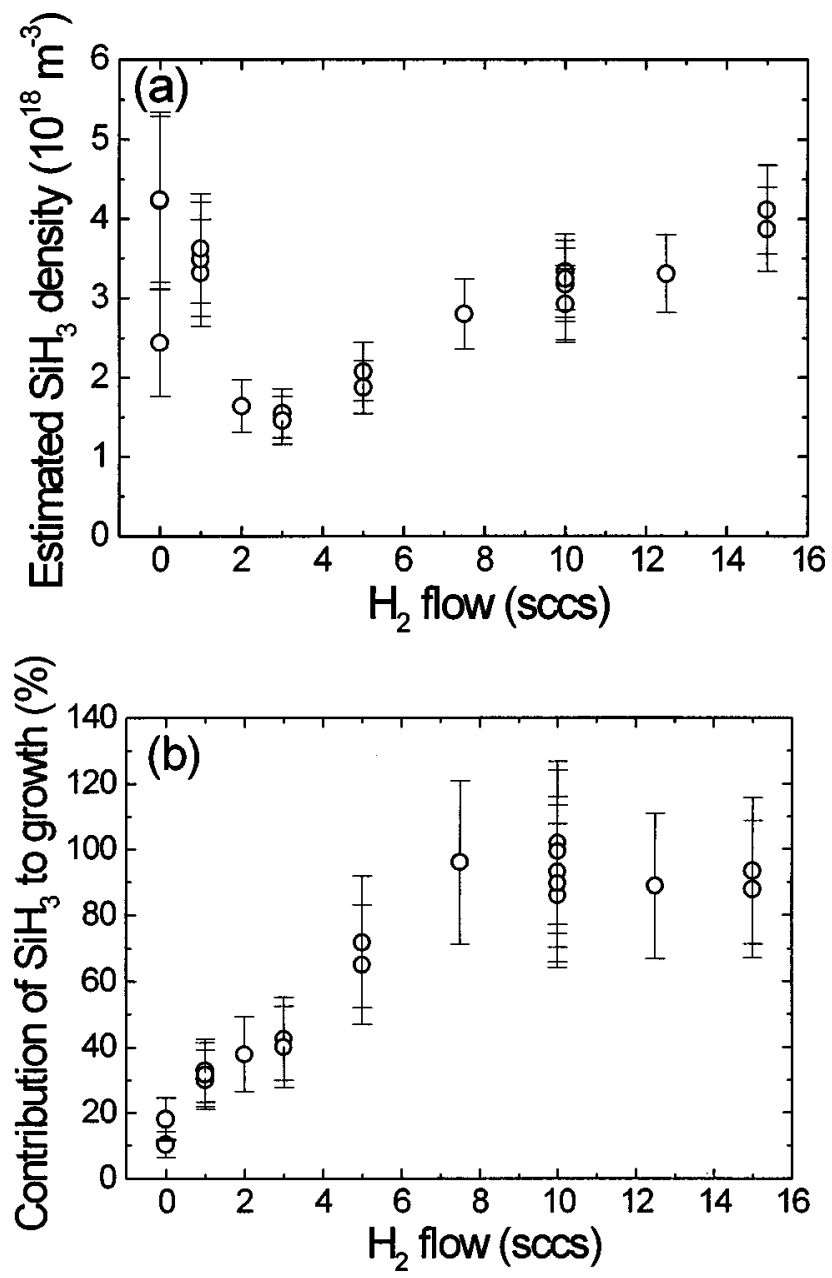

FIG. 4. (a) $\mathrm{SiH}_{3}$ density obtained from threshold ionization mass spectrometry and (b) contribution of $\mathrm{SiH}_{3}$ to $a-\mathrm{Si}: \mathrm{H}$ film growth as a function of $\mathrm{H}_{2}$ flow $\left(\mathrm{SiH}_{4}\right.$ flow is $\left.10 \mathrm{sccs}\right)$.

is not accurately known within a factor of 2 . Therefore, another method is proposed which is, in our opinion, more reliable. However, not generally applicable: as the increase of the $\mathrm{H}_{2}$ flow from 10 to 15 sccs leads only to more $\mathrm{H}$ from the arc (the ion flow slightly decreases ${ }^{16}$ ), it is plausible that the increase in $\mathrm{SiH}_{4}$ consumption and $a-\mathrm{Si}: \mathrm{H}$ deposition rate between 10 and $15 \mathrm{sccs}$ (see Fig. 2) is completely due to a higher $\mathrm{SiH}_{3}$ density. Linking the increase in deposition rate to the increase in $\mathrm{SiH}_{3}$ signal, a direct relation between the $\mathrm{SiH}_{3}$ signal and the deposition rate is obtained, from which the contribution of $\mathrm{SiH}_{3}$ to film growth, as given in Fig. 4(b), can be calculated. The absolute value of the presented contribution relies, of course, fully on the above assumption with respect to the increase in deposition rate between 10 and $15 \mathrm{sccs} \mathrm{H}_{2}$. However, as will be shown below, this assumption is also plausible on the basis of the other results with respect to the plasma chemistry and the surface reaction probability. It is, therefore, expected that the presented values of the absolute contribution are much more accurate than estimations on the basis of the $\mathrm{SiH}_{3}$ density. We note however, that both methods yield the same relative dependence of the contribution of $\mathrm{SiH}_{3}$ to film growth, while the absolute 
values of the contributions in Fig. 4(b) are not in contradiction with those calculated from the $\mathrm{SiH}_{3}$ densities in Fig. 4(a) when reasonable values for $v$ and $s$ of $\mathrm{SiH}_{3}$ are applied. In Fig. 4(b) there is still some uncertainty in the exact contribution, mainly due to the fact that the deposition rate and $\mathrm{SiH}_{3}$ density have been determined in different experiments, but it is clear that the contribution of $\mathrm{SiH}_{3}$ increases with $\mathrm{H}_{2}$ flow and saturates at higher $\mathrm{H}_{2}$ flows (where it dominates film growth with a contribution of around 90\%).

Figure 4(b) shows that at low- $\mathrm{H}_{2}$ flows, other species than $\mathrm{SiH}_{3}$ contribute significantly to film growth. As mentioned above, at these flows $\mathrm{SiH}_{4}$ dissociation is governed by reactions induced by positive ions emanating from the plasma source. $\mathrm{Ar}^{+}$and $\mathrm{H}^{+}$can undergo dissociative charge transfer with $\mathrm{SiH}_{4}$ leading to silane ions $\mathrm{SiH}_{n}^{+}\left(n \leqslant 3, \mathrm{SiH}_{4}^{+}\right.$is unstable ${ }^{40}$ ):

$$
\operatorname{Ar}^{+}\left(\mathrm{H}^{+}\right)+\mathrm{SiH}_{4} \rightarrow \mathrm{SiH}_{n}^{+}+p \mathrm{H}_{2}+q \mathrm{H}+\mathrm{Ar} \quad(n \leqslant 3) .
$$

The reported reaction rates $k_{\text {ch.ex. }}$ for $\mathrm{Ar}^{+}$are in the order of $10^{-16} \mathrm{~m}^{3} \mathrm{~s}^{-1}$ and at thermal energies mainly $\mathrm{SiH}_{3}^{+}$is created. ${ }^{40}$ For $\mathrm{H}^{+}$only a rate for the reaction leading to $\mathrm{SiH}_{3}^{+}$ has been proposed, which is equal to $5 \times 10^{-15} \mathrm{~m}^{3} \mathrm{~s}^{-1}$. ${ }^{40} \mathrm{Si}$ lane ions initiate cationic cluster $\mathrm{Si}_{n} \mathrm{H}_{m}^{+}$formation by sequential ion-molecule reactions with $\mathrm{SiH}_{4} \cdot{ }^{15,16,41}$

$$
\mathrm{Si}_{n} \mathrm{H}_{m}^{+}+\mathrm{SiH}_{4} \rightarrow \mathrm{Si}_{n+1} \mathrm{H}_{p}^{+}+q \mathrm{H}_{2},
$$

with rates $k_{\text {ion-mol }}$ estimated at $\sim 10^{-16} \mathrm{~m}^{3} \mathrm{~s}^{-1}$. It has been shown that the contribution of the positive ions to film growth is less than $10 \%$ in terms of $\mathrm{Si}$ atoms deposited. ${ }^{16}$ The previously used assumption that $s=1$ for these ions has recently been justified by molecular dynamics studies which yielded $s>0.85$ for all types of hydrogenated Si surfaces. ${ }^{42}$ Remarkable is that the contribution of the ions is rather independent of the $\mathrm{H}_{2}$ flow admixed in the arc, while the ion fluence from the arc is heavily dependent on this $\mathrm{H}_{2}$ flow. ${ }^{16}$ This can be understood from dissociative recombination reactions of silane ions with electrons:

$$
\mathrm{SiH}_{n}^{+}+e \rightarrow \mathrm{SiH}_{m}+p \mathrm{H}+q \mathrm{H}_{2} \quad(n \leqslant 2),
$$

with reaction rates $k_{\mathrm{rec}}$ in the order of $10^{-13} T_{e}^{-1 / 2} \mathrm{~m}^{3} \mathrm{~s}^{-1}\left(T_{e}\right.$ in $\mathrm{eV}){ }^{40}$ These reactions compete with the ion-molecule reactions (7), but as long as the product of the reaction rate for dissociative recombination and the electron density is much larger than the product of the reaction rate for ionmolecule reactions and the $\mathrm{SiH}_{4}$ density, i.e., $k_{\text {rec }} n_{e}$ $\gg k_{\text {ion-mol }} n_{\mathrm{SiH}_{4}}$, dissociative recombination will prevail. This is certainly the case at low- $\mathrm{H}_{2}$ flows where $n_{e}$ is high ${ }^{16}$ and dissociative recombination occurs almost instantaneously after reaction (6), leading to a significant production of radicals like $\mathrm{SiH}_{2}, \mathrm{SiH}$, and $\mathrm{Si}$. The rather constant contribution of the cationic clusters is explained by the fact that the ionmolecule reactions can only get important when $n_{e}$ is significantly reduced by reaction (8). For a $\mathrm{SiH}_{4}$ density of $\sim 10^{20} \mathrm{~m}^{-3}$ this is expected to occur at $n_{e} \approx 10^{17} \mathrm{~m}^{-3}$, which is roughly equal to the value of $n_{e}$ at higher $\mathrm{H}_{2}$ flows.

From reaction (6) and (8), the relatively high $\mathrm{SiH}_{3}$ density at low- $\mathrm{H}_{2}$ flows can also be understood. In both reactions, $\mathrm{H}$

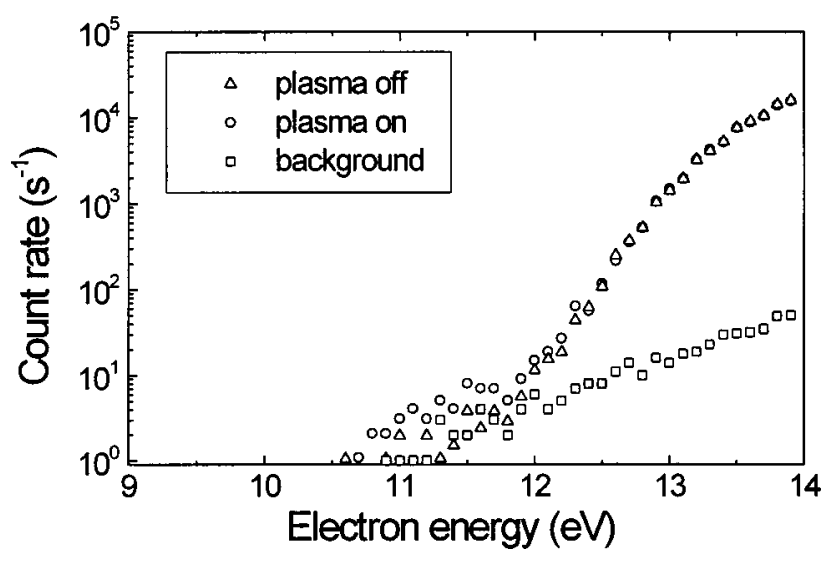

FIG. 5. Electron energy scan at $m / e=30$ for detection of $\mathrm{SiH}_{2}$. The values for "plasma off" are normalized to those of "plasma on", at high electron energies. The $\mathrm{H}_{2}$ flow is 0 sccs and the $\mathrm{SiH}_{4}$ flow is 10 sccs. The background signal, obtained with $\mathrm{SiH}_{4}$ flow $=0$ sccs, is due to a contaminant in the mass spectrometer.

can be generated which can subsequently react with $\mathrm{SiH}_{4}$ creating $\mathrm{SiH}_{3}$ [reaction (5)]. This can lead to a considerable density of $\mathrm{SiH}_{3}$ under conditions where the $\mathrm{SiH}_{4}$ consumption is high, and it explains the initial decrease of the $\mathrm{SiH}_{3}$ density at low- $\mathrm{H}_{2}$ flows. Another possible reaction that can generate $\mathrm{SiH}_{3}$ from the reaction products of reaction (6) is

$$
\mathrm{SiH}_{2}^{+}+\mathrm{SiH}_{4} \rightarrow \mathrm{SiH}_{3}^{+}+\mathrm{SiH}_{3} \text {. }
$$

On the basis of the aforementioned reasoning, this reaction with a rate of $\sim 10^{-15} \mathrm{~m}^{3} \mathrm{~s}^{-1}$ (Ref. 40) will become as important as dissociative recombination when $n_{e}$ is reduced to $\sim 10^{18} \mathrm{~m}^{-3}$.

In order to measure the radicals created in reaction (8), threshold ionization mass spectrometry has been applied. $\mathrm{SiH}_{2}$ radicals could only be detected for $\mathrm{H}_{2}=0$ sccs, where the $\mathrm{SiH}_{2}$ production is also expected to be at maximum. As shown in Fig. 5, the radical signal is rather weak (estimation of the $\mathrm{SiH}_{2}$ density on the basis of the procedure described in Sec. II B yields $\sim 10^{18} \mathrm{~m}^{-3}$ at 0 sccs $\mathrm{H}_{2}$ ) and the $\mathrm{SiH}_{2}$ density in front of the substrate holder is apparently too low for the measurements at nonzero $\mathrm{H}_{2}$ flows. It should be noted that detection of $\mathrm{SiH}_{2}$ is more complicated than the detection of $\mathrm{SiH}_{3}$. First, $\mathrm{SiH}_{2}$ has a higher surface reaction probability than $\mathrm{SiH}_{3},{ }^{28}$ which can lead to a higher loss of $\mathrm{SiH}_{2}$ during extraction from the plasma. Second, the difference between the ionization potential of $\mathrm{SiH}_{2}$ and the appearance potential of $\mathrm{SiH}_{2}{ }^{+}$from $\mathrm{SiH}_{4}$ is smaller, ${ }^{26}$ while at $m / e=30$ a strong residual signal due to contamination in the mass spectrometer appears at slightly lower electron energies than the appearance potential (see Fig. 5). This residual signal, which is not related to the $\mathrm{SiH}_{4}$ flow, is measured in pure Ar. Although its origin is still unclear, $\mathrm{NO}^{+}$created by ionization of NO is a likely candidate. This radical, possibly created at the hot filament from residual $\mathrm{N}_{2}$ and $\mathrm{O}_{2}$, has an ionization potential around $10 \mathrm{eV} .^{43}$

The presence of contamination together with a relatively low density in front of the mass spectrometer are probably 
also the reasons why $\mathrm{SiH}$ and $\mathrm{Si}$ radicals could not be detected. The low radical densities can be due to a small production rate or to a large loss rate, e.g., by fast reactions with $\mathrm{SiH}_{4}$ as will be addressed in Sec. IV. Furthermore, for the present setup the detection limit of the radicals is rather high due to the interfering high residual gas density in the mass spectrometer, as discussed in Sec. II B.

Although the reaction pathway proposed is not counter to the fact that $\mathrm{SiH}_{2}$ has only been detected for 0 sccs $\mathrm{H}_{2}$ and that $\mathrm{SiH}$ and $\mathrm{Si}$ could not be observed at all, optical emission spectroscopy has been applied to find more confirmation. The $A^{2} \Delta-X^{2} \Pi$ electronic transition band of $\mathrm{SiH}$ at $\sim 414$ $\mathrm{nm}$ and the Si I $4 s^{1} P^{0}-3 p^{21} S$ transition at $390.6 \mathrm{~nm}$, represented, respectively, by $\mathrm{SiH}^{*}$ and $\mathrm{Si}^{*}$, have been studied. Unlike conventional plasmas, $T_{e}$ in the downstream region is too low for the creation of these electronically excited species by electron-induced excitation or dissociation to be significant. Accordingly, $\mathrm{Si}^{*}$ and $\mathrm{SiH}^{*}$ are mainly created by dissociative recombination of $\mathrm{SiH}_{n}{ }^{+}$with electrons [reaction (8)], where enough energy is available for electronic excitation of the produced silane radicals. Therefore, it is believed that the emission of these excited species is an indication of the occurrence of reaction (8). Because of their fast radiative decay [radiative lifetime $\tau$ for $\mathrm{Si} \mathrm{I}^{1} s^{1} P^{0}$ and $\mathrm{SiH} A^{2} \Delta$ is, respectively, 4.1 and 534 ns (Ref. 44)], their emission is expected to be proportional to the number of recombination events. On the basis of this, the emission intensity per unit of time displayed in Fig. 6(a), reveals that more dissociative recombination takes place at low- $\mathrm{H}_{2}$ flows when more ions emanate from the arc. The fact that both the $\mathrm{SiH}^{*}$ and $\mathrm{Si}^{*}$ emissions show the same dependence validates the assumption that a fixed percentage (i.e., independent of $\mathrm{H}_{2}$ flow) of the reaction products in reaction (8) are $\mathrm{SiH}^{*}$ and $\mathrm{Si}^{*}$. In Fig. 6(b), the emission intensity is corrected for the total amount of $\mathrm{SiH}_{4}$ consumed showing that reactions (6) and (8) are relatively more important at low- $\mathrm{H}_{2}$ flows, in agreement with the reaction pathway proposed.

The assumption that the emission by $\mathrm{SiH}^{*}$ and $\mathrm{Si}^{*}$ displays in fact the recombination of silane ions can roughly be validated by relating the emission intensity to the ion fluence from the arc. From stationary rate equations for reactions (6), (7), and (8) a local radiative decay rate for the excited species can be calculated:

$$
\frac{n_{\mathrm{SiH}_{x}^{*}}}{\tau}=\frac{n_{\mathrm{Ar}^{+} / \mathrm{H}^{+}} n_{\mathrm{SiH}_{4}} k_{\text {ch.ex. }}}{n_{e} k_{\mathrm{rec}}+n_{\mathrm{SiH}_{4}} k_{\text {ion }-\mathrm{mol}}} n_{e} k_{\mathrm{rec}},
$$

where $n_{\mathrm{SiH}_{x}^{*}}$ is the density of the excited species and $n_{\mathrm{Ar}^{+} / \mathrm{H}^{+}}$ the density of $\mathrm{Ar}^{+}$and $\mathrm{H}^{+}$from the arc. At low $\mathrm{H}_{2}$ flows the ion-molecule reactions (second term in the denominator) can be neglected compared to dissociative recombination which leads to a radiative decay rate linear in the $\mathrm{Ar}^{+} / \mathrm{H}^{+}$ ion density. Assuming a similar global behavior, it is expected that at low- $\mathrm{H}_{2}$ flows the total radiative decay rate is linear in the ion fluence from the arc. This is indeed true for the emission intensity per unit of time (integrated over a
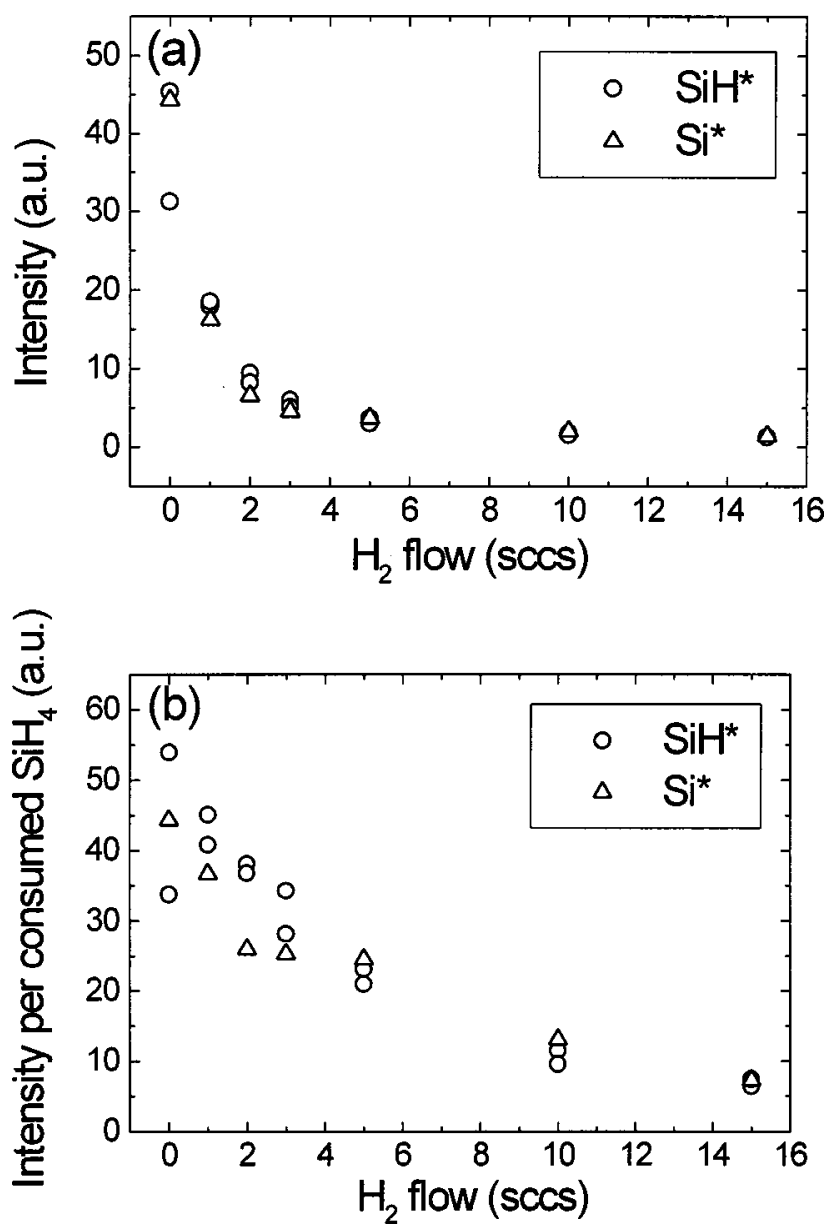

Fig. 6. (a) Emission intensity of $\mathrm{SiH}^{*}\left(A^{2} \Delta-X^{2} \Pi\right)$ and $\mathrm{Si}^{*}\left(4 s^{1} P^{0}\right.$ $-3 p^{21} S$ ) per unit of time. The $\mathrm{SiH}_{4}$ flow is 10 sccs. (b) Emission intensity divided by $\mathrm{SiH}_{4}$ consumption (in arbitrary units).

large part of the downstream region), as can be seen in Fig. 7 , where the slope of the fit in the double-log plot is almost equal to $1(0.90)$.

The rotational and vibrational temperatures of the excited $\mathrm{SiH}$ radical are shown in Fig. 8 and do not show a clear dependence on the $\mathrm{H}_{2}$ flow. This implies an excitation mechanism that is independent of the $\mathrm{H}_{2}$ flow. The vibrational temperature is around $3000 \mathrm{~K}$ and the rotational temperature is between 1400 and $1500 \mathrm{~K}$. The gas temperatures in the expanding thermal plasma are in the range 1000$1500 \mathrm{~K}^{23,24}$

The increasing contribution of $\mathrm{SiH}_{3}$ and the decreasing production of $\mathrm{SiH}_{x}(x \leqslant 2)$ radicals for increasing $\mathrm{H}_{2}$ flow are expected to affect the overall surface reaction probability $\beta_{0}$, which depends on the relative contribution of the different species and their surface reaction probability $\beta$. For $\mathrm{SiH}_{3}$ the reported values of $\beta$ are within the range $0.1-0.3$, while for $\operatorname{SiH}_{x}(x \leqslant 2)$, values in the range $0.6-1$ have been reported. ${ }^{28}$ This explains the decrease of $\beta_{0}$ with increasing $\mathrm{H}_{2}$ flow, as shown in Fig. 9. Values of $\beta_{0}$ estimated on the basis of the presented contributions of $\mathrm{SiH}_{3}$ and $\mathrm{Si}_{n} \mathrm{H}_{m}^{+}$and the production of $\mathrm{SiH}_{x}(x \leqslant 2)$ radicals are also given in Fig. 9. These values are obtained by the procedure described in 


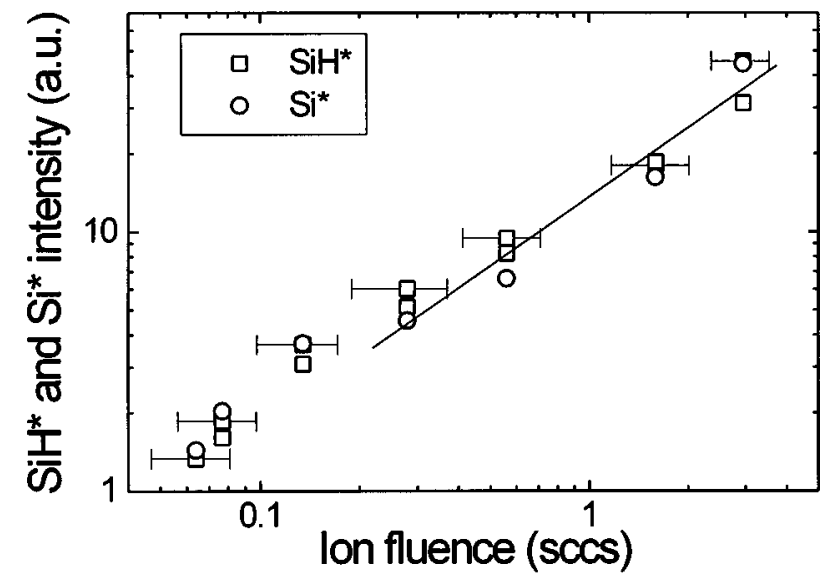

FIG. 7. Emission intensity of $\mathrm{SiH}^{*}$ and $\mathrm{Si}^{*}$ from Fig. 6(a) as a function of the ion fluence emanating from the arc. The line is a fit to the data points for $\mathrm{H}_{2}<5 \mathrm{sccs}$, where the ion-molecule reactions can be neglected compared to dissociative recombination reactions.

Ref. 28 using $s=\beta=0.28$ for $\mathrm{SiH}_{3}, s=\beta=1$ for $\mathrm{Si}_{n} \mathrm{H}_{m}^{+}$, and $s=\beta=0.6$ for $\mathrm{SiH}_{x}(x \leqslant 2)$, independent of the $\mathrm{H}_{2}$ flow. The values from this simplified estimation show fairly good agreement. The rather low $\beta$, which needs to be assumed for $\mathrm{SiH}_{x}(x \leqslant 2)$, can possibly be explained by the fact that these radicals are very reactive with $\mathrm{SiH}_{4}$ and can have reacted to polysilane radicals (with possibly a lower $\beta$ ) before reaching the substrate (see Sec. IV).

\section{B. $\mathrm{SiH}_{4}$ flow series}

The influence of the partial pressure of $\mathrm{SiH}_{4}$ on the plasma processes has been studied by varying the $\mathrm{SiH}_{4}$ flow while keeping the plasma source conditions fixed. The $\mathrm{H}_{2}$ flow in the arc is set at 10 sccs because for this condition mainly $\mathrm{H}$ emanates from the source and the best $a-\mathrm{Si}: \mathrm{H}$ film properties have been obtained.

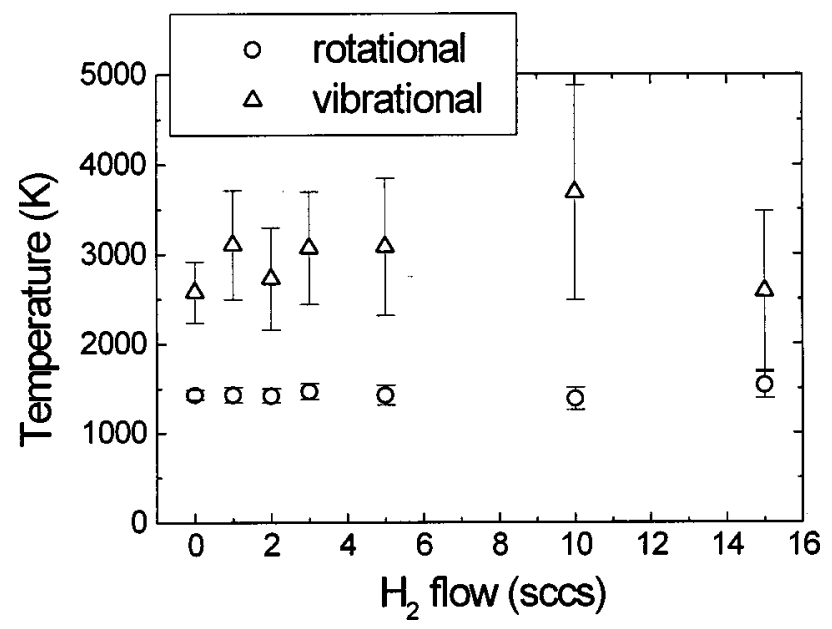

FIG. 8. Vibrational and rotational temperatures of $\mathrm{SiH}^{*}$ obtained from the fit to the experimental spectrum of the $A^{2} \Delta-X^{2} \Pi$ transition. The $\mathrm{SiH}_{4}$ flow is 10 sccs.

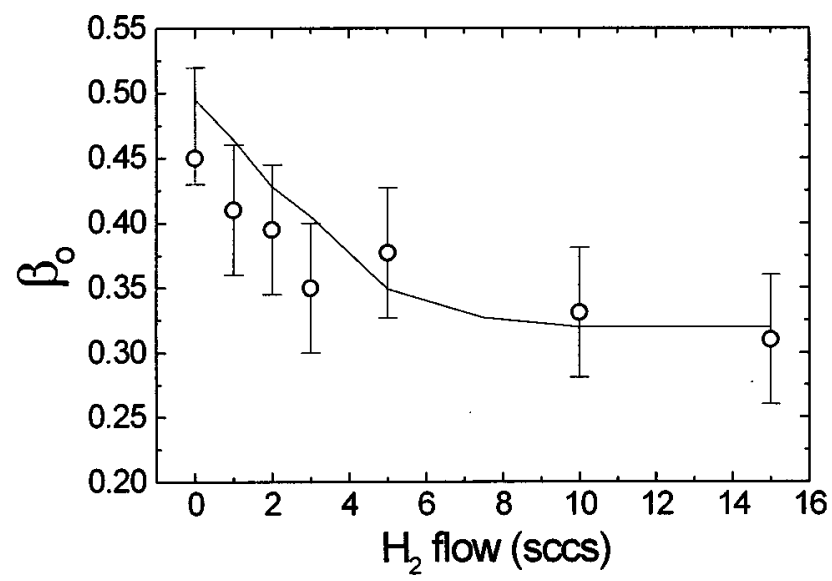

FIG. 9. Overall surface reaction probability $\beta_{0}$ as determined from aperturewell experiments for $10 \mathrm{sccs} \mathrm{SiH}_{4}$ and varying $\mathrm{H}_{2}$ flows. The line represents estimations of $\beta_{0}$ on the basis of the contributions of the different species to film growth. Further explanation is given in the text.

The consumed $\mathrm{SiH}_{4}$ flow and corresponding deposition rate are given in Fig. 10. The $\mathrm{SiH}_{4}$ consumption increases with $\mathrm{SiH}_{4}$ flow and it can roughly be divided into two regions. Up to $\sim 3 \operatorname{sccs}$ the increase is steeper than at higher flows where the $\mathrm{SiH}_{4}$ consumption increases only gradually with $\mathrm{SiH}_{4}$ flow. It means that at low- $\mathrm{SiH}_{4}$ flows a larger fraction of the $\mathrm{SiH}_{4}$ is consumed than at higher flows. This behavior suggests that the amount of $\mathrm{H}$ available for $\mathrm{SiH}_{4}$ dissociation is the limiting factor, whereas the total flow of $\mathrm{SiH}_{4}$ consumed at high- $\mathrm{SiH}_{4}$ flows is about equal to the forward flow of $\mathrm{H}$ as estimated from the TALIF measurements (see Sec. II A). It corroborates that a considerable amount of $\mathrm{H}$ from the cascaded arc is lost before it can dissociate $\mathrm{SiH}_{4}{ }^{22}$

In Fig. 11(a) the $\mathrm{SiH}_{3}$ density is given, showing the same dependence on the $\mathrm{SiH}_{4}$ flow as the $\mathrm{SiH}_{4}$ consumption. Consequently, the contribution of $\mathrm{SiH}_{3}$ to film growth, as shown in Fig. 11(b) and calculated by the method described in Sec. III A, is fairly constant for the different $\mathrm{SiH}_{4}$ flows. This means that $\mathrm{SiH}_{3}$ dominates film growth independent of the $\mathrm{SiH}_{4}$ flow and for deposition rates ranging from 1 to $10 \mathrm{~nm} / \mathrm{s}$.

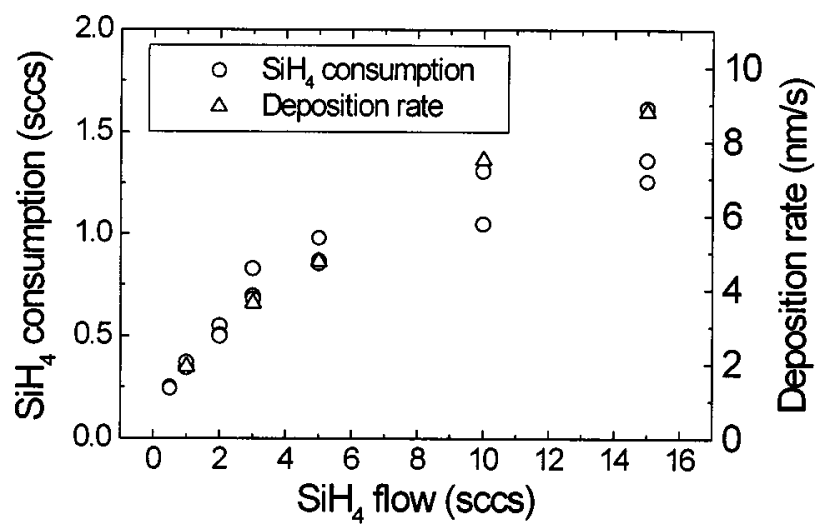

FIG. 10. Consumption of $\mathrm{SiH}_{4}$ expressed in equivalent flow for constant $\mathrm{H}_{2}$ flow $(10 \mathrm{sccs})$ in the arc. The corresponding deposition rate for a substrate temperature of $400{ }^{\circ} \mathrm{C}$ is given on the right axis. 

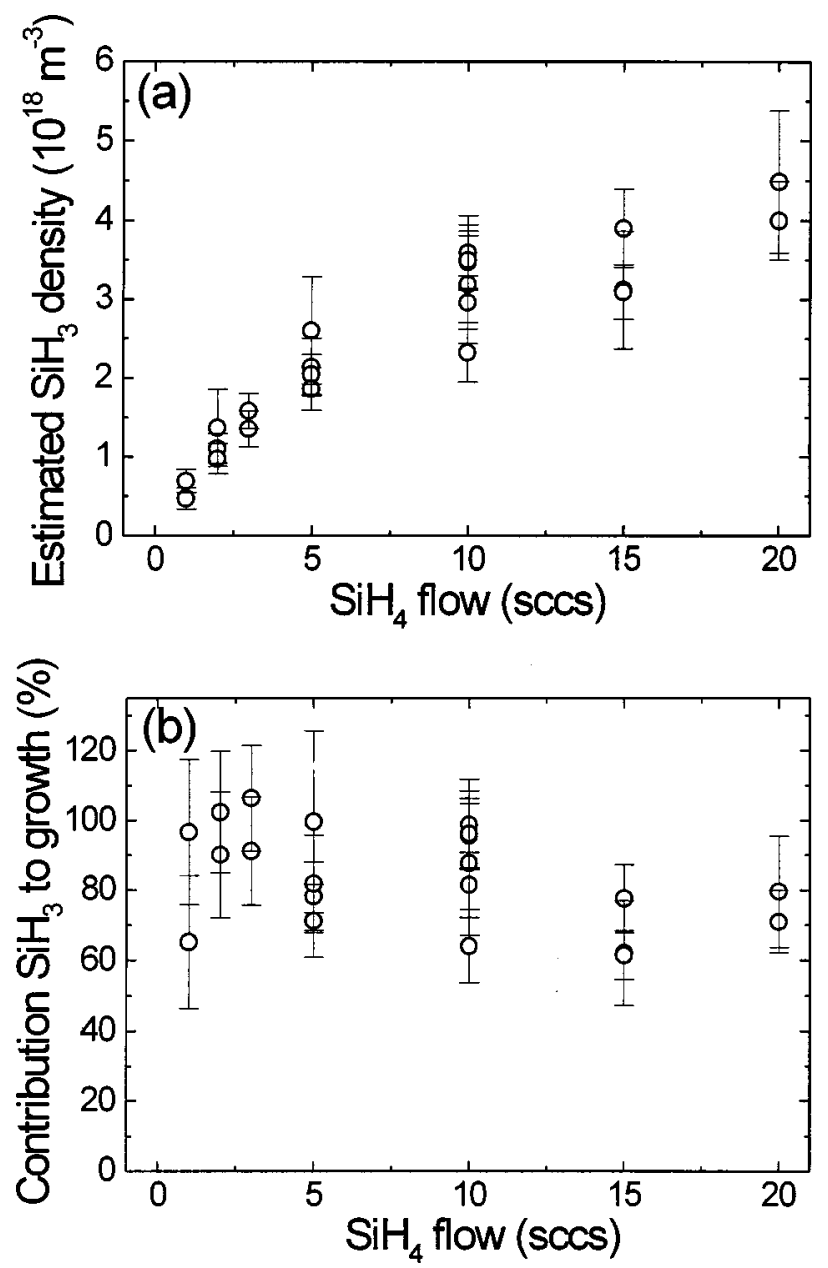

FIG. 11. (a) $\mathrm{SiH}_{3}$ density obtained from threshold ionization mass spectrometry and (b) contribution of $\mathrm{SiH}_{3}$ to $a$ - $\mathrm{Si}: \mathrm{H}$ film growth as a function of $\mathrm{SiH}_{4}$ flow $\left(\mathrm{H}_{2}\right.$ flow is $\left.10 \mathrm{sccs}\right)$.

The rather constant contribution of $\mathrm{SiH}_{3}$ has implications for reactions that affect the $\mathrm{SiH}_{3}$ density. Hydrogen abstraction by $\mathrm{H}$ from $\mathrm{SiH}_{3}$ :

$$
\mathrm{H}+\mathrm{SiH}_{3} \rightarrow \mathrm{SiH}_{2}+\mathrm{H}_{2},
$$

has a considerable reaction rate at $300 \mathrm{~K}$ $\left(2 \times 10^{-17} \mathrm{~m}^{3} \mathrm{~s}^{-145}\right)$ in comparison with reaction $(5)$, and the rate for the disproportion reaction between two $\mathrm{SiH}_{3}$ radicals:

$$
\mathrm{SiH}_{3}+\mathrm{SiH}_{3} \rightarrow \mathrm{SiH}_{2}+\mathrm{SiH}_{4}
$$

is even higher $\left[\sim 10^{-16} \mathrm{~m}^{3} \mathrm{~s}^{-1}\right.$ at $300 \mathrm{~K}$ (Refs. 40 and 45 )]. These reactions lead to $\mathrm{SiH}_{2}$ production, and especially reaction (12) can become very important at high- $\mathrm{SiH}_{4}$ flows as it is quadratically dependent on the $\mathrm{SiH}_{3}$ density. These reactions are apparently not very important, as they would lead to an increasing contribution of $\mathrm{SiH}_{2}$, or its reaction products (polysilane radicals) with $\mathrm{SiH}_{4}$, to film growth at the expense of the contribution of $\mathrm{SiH}_{3}$. This is not obvious in Fig. 11(b).

The missing fraction of film growth in Fig. 11(b) takes place by positive ions and radicals other than $\mathrm{SiH}_{3}$. As addressed in Refs. 15 and 16, the contribution of ions is almost

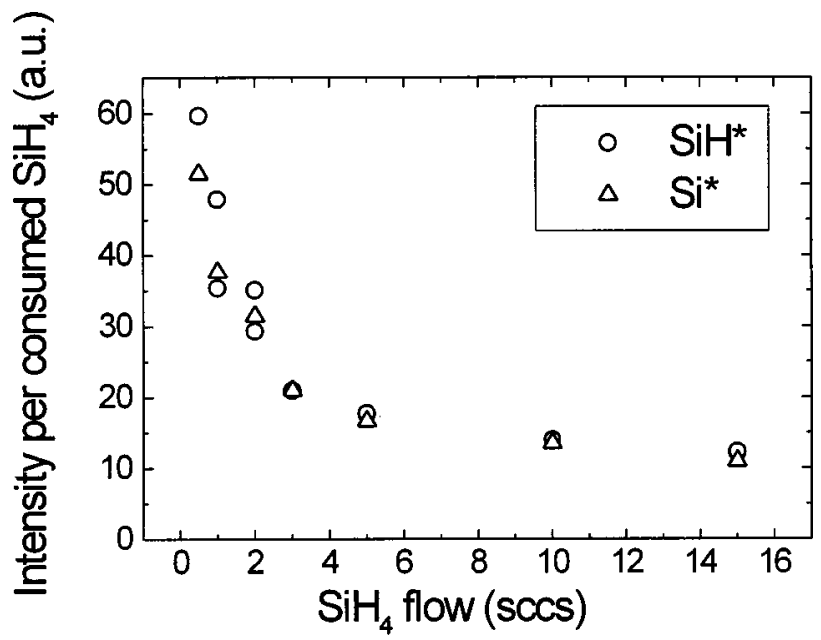

FIG. 12. Emission intensity of $\operatorname{SiH}^{*}\left(A^{2} \Delta-X^{2} \Pi\right)$ and $\mathrm{Si}^{*}\left(4 s^{1} P^{0}-3 p^{21} S\right)$ per unit of time and divided by $\mathrm{SiH}_{4}$ consumption (in arbitrary units). $\mathrm{H}_{2}$ flow is fixed at 10 sccs.

independent of the $\mathrm{SiH}_{4}$ flow and less than 7\%, while the average number of $\mathrm{Si}$ atoms per ion increases with $\mathrm{SiH}_{4}$ flow. The ion size has implications for the products created by dissociative recombination of the ions. Although less frequent, recombination will still take place under this condition with relatively low $n_{e}$ and it is expected that the rate for dissociative recombination of the ions with electrons does not heavily depend on the size of the ions. ${ }^{16,40}$ At low-SiH 4 flows there are relatively more silane ions $\mathrm{SiH}_{n}^{+}$and their recombination leads to $\mathrm{SiH}_{x}(x \leqslant 2)$ radicals (and, thus, to $\mathrm{SiH}^{*}$ and $\left.\mathrm{Si}^{*}\right)$ while the recombination of the cationic clusters at larger $\mathrm{SiH}_{4}$ flows most probably leads to larger neutral fragments. It is, therefore, expected that the emission of $\mathrm{SiH}^{*}$ and $\mathrm{Si}^{*}$ is relatively stronger at low- $\mathrm{SiH}_{4}$ flows. This is indeed the case, as can be seen in Fig. 12, and it provides more evidence for the reaction pathway for cationic cluster formation proposed in Ref. 15. Furthermore, the rotational and vibrational temperatures of the excited $\mathrm{SiH}$ radical (not shown) do not show a clear dependence on the $\mathrm{SiH}_{4}$ flow and are, respectively, about 1500 and $3000 \mathrm{~K}$, as in Fig. 8.

\section{DISCUSSION}

From the combination of the results obtained by the different diagnostics, the dissociation mechanisms of $\mathrm{SiH}_{4}$ in the expanding thermal plasma are fairly well understood. For the $\mathrm{H}_{2}$ flow series, it is convincingly shown that the contribution of $\mathrm{SiH}_{3}$ increases with $\mathrm{H}_{2}$ flow and becomes constant for $\mathrm{H}_{2}$ flows $>7.5$ sccs. This is independent of the assumption used to determine the absolute contribution to film growth. The latter assumption, which leads to the conclusion that $\mathrm{SiH}_{3}$ dominates the deposition process for high- $\mathrm{H}_{2}$ flows with an estimated absolute contribution of around 90\%, seems, however, very plausible and is corroborated by the value of the overall surface probability $\beta_{0}$ of $\sim 0.3$ at high$\mathrm{H}_{2}$ flows. The absolute $\mathrm{SiH}_{3}$ density in Fig. 4(a) can fully account for the presented contribution of $\mathrm{SiH}_{3}$ to film growth, but the calculation of the contribution of $\mathrm{SiH}_{3}$ on the 
basis of this density leaves too much freedom in the absolute value due to uncertainties in the absolute density of $\mathrm{SiH}_{3}$ itself (mainly due to the factor $C$ ) as well as in $v$ and $s$. It is therefore, expected that the presented method is much more accurate, although the estimation of the exact contribution is, of course, very sensitive on the accuracy and reproducibility of the deposition rate and $\mathrm{SiH}_{3}$ signal.

At lower $\mathrm{H}_{2}$ flows, it is shown that there needs to be a significant contribution of radicals other than $\mathrm{SiH}_{3}$ as the contribution of positive ions does not compensate for the lower contribution of $\mathrm{SiH}_{3}$. Figure 6(b) suggests that the production of $\mathrm{SiH}_{x}(x \leqslant 2)$ from dissociative recombination is about a factor of 6 larger at $\mathrm{H}_{2}=0 \mathrm{sccs}$ than at $\mathrm{H}_{2}$ $=10 \mathrm{sccs}$. This roughly compensates the decrease in contribution of $\mathrm{SiH}_{3}$, as shown in Fig. 4(b), but it is premature to conclude that $\mathrm{SiH}_{x}(x \leqslant 2)$ radicals govern film growth at low- $\mathrm{H}_{2}$ flows. First of all, the emission intensity in Fig. 6 is not collected in the whole deposition chamber, making it difficult to speculate about how many more recombination events there are at low- $\mathrm{H}_{2}$ flows. Second, in the determination of the contribution of $\mathrm{SiH}_{3}$ it is assumed that $\beta$ and $s$ of $\mathrm{SiH}_{3}$ are independent of the $\mathrm{H}_{2}$ flow. It can, however, not be excluded that $\beta$ and $s$ are somewhat higher at low- $\mathrm{H}_{2}$ flows due to a higher reactivity of the $a-\mathrm{Si}: \mathrm{H}$ surface. For example, the higher contribution of $\mathrm{SiH}_{x}(x \leqslant 2)$ radicals can lead to more surface dangling bonds. This would also contribute to the increase of $\beta_{0}$ in Fig. 9. But, most important is that the emission intensity is only an indication of the recombination of silane ions. It does not reveal information on the specific species created, and finally contributing to film growth. As mentioned before, the radicals produced in reaction (8) have a rather high reactivity with $\mathrm{SiH}_{4}$ and can be converted into other species before reaching the substrate. Contrary to $\mathrm{SiH}_{3}$, which is not very reactive with $\mathrm{SiH}_{4}$ [reaction rate $<4$ $\times 10^{-20} \mathrm{~m}^{3} \mathrm{~s}^{-1}$ at $300 \mathrm{~K}$ (Ref. 45)], reaction rates in the order $10^{-16}-10^{-17} \mathrm{~m}^{3} \mathrm{~s}^{-1}$ [at $\sim 0.2$ mbar and $300 \mathrm{~K}$ (Refs. 40, 46, and 47)] have been proposed for $\mathrm{SiH}_{2}, \mathrm{SiH}$, and $\mathrm{Si}$. This means that for a typical $\mathrm{SiH}_{4}$ density of $\sim 10^{20} \mathrm{~m}^{-3}$, the radicals have reacted with $\mathrm{SiH}_{4}$ within 50-500 $\mu$ s, and this is shorter than the transport time of the radicals to the substrate $(\sim 500-1000 \mu \mathrm{s})$. This shows that the influence of the radicals created from reaction (8) cannot be derived simply from Fig. 6 and that additional, more extensive investigations are required.

Although still some questions remain unanswered, a correlation between the reaction products of $\mathrm{SiH}_{4}$ dissociation and the $a$-Si:H film quality can already be made. This will be discussed only briefly, as it will be addressed more extensively in another article, where also the film properties for the different plasma conditions are given. ${ }^{14}$ As mentioned earlier, a considerable $\mathrm{H}_{2}$ flow in the arc is necessary to obtain good film properties (the optimum film quality is obtained with $10 \mathrm{sccs} \mathrm{H}_{2}$ and $10 \mathrm{sccs} \mathrm{SiH}_{4}$ flow), which shows the importance of the contribution of $\mathrm{SiH}_{3}$ to film growth. The optoelectronic film properties depend strongly on the $\mathrm{H}_{2}$ flow while the structural film properties only become inferior at very low- $\mathrm{H}_{2}$ flows $(<2$ sccs $)$. Under these conditions,
$a$-Si:H is obtained that contains a considerable void fraction. This can be understood from a significant contribution of radicals with a very high $\beta$ and is also in line with the higher surface roughness of the films as determined by in situ ellipsometry. ${ }^{48}$ That film growth dominated by $\mathrm{SiH}_{3}$ does not automatically lead to good film quality can be seen from the deterioration of the film properties for decreasing $\mathrm{SiH}_{4}$ flow. Under these conditions, the contribution of $\mathrm{SiH}_{3}$ to film growth is about constant, while both structural and optoelectronic properties are inferior at low- $\mathrm{SiH}_{4}$ flows $(<3 \mathrm{sccs})$. This is less understood, but it can possibly be attributed to the fact that at low- $\mathrm{SiH}_{4}$ flows the reaction products from dissociative recombination are smaller. Their impact on the film quality could be different from the impact of larger neutral fragments created by recombination of cationic clusters at larger $\mathrm{SiH}_{4}$ flows. For example, the small $\mathrm{Si}$ and $\mathrm{SiH}$ radicals can penetrate the subsurface region ${ }^{49}$ and introduce dangling bonds in the film, which can degrade the film properties.

\section{CONCLUSIONS}

The dissociation of $\mathrm{SiH}_{4}$ in the expanding thermal plasma used for high-rate deposition of device-quality $a$-Si:H has been investigated by different plasma diagnostics. The density of $\mathrm{SiH}_{3}$ has been determined by threshold ionization mass spectrometry and the contribution of $\mathrm{SiH}_{3}$ to $a-\mathrm{Si}: \mathrm{H}$ film growth has been determined without using estimates on the $\mathrm{SiH}_{3}$ thermal velocity and sticking probability. It is shown that at high- $\mathrm{H}_{2}$ flows $\mathrm{SiH}_{4}$ dissociation mainly takes place by hydrogen abstraction by $\mathrm{H}$ emanating from the $\mathrm{Ar}-\mathrm{H}_{2}$-operated plasma source. Under these conditions, film growth is dominated by $\mathrm{SiH}_{3}$ (estimated contribution 90\%) and the best $a-\mathrm{Si}: \mathrm{H}$ film quality is obtained.

The contribution of $\mathrm{SiH}_{3}$ decreases with decreasing $\mathrm{H}_{2}$ flow and at low- $\mathrm{H}_{2}$ flows the dissociation of $\mathrm{SiH}_{4}$ is dominated by reactions with ions from the plasma source. As confirmed by optical emission spectroscopy on excited $\mathrm{Si}$ and $\mathrm{SiH}$, this causes strong dissociative recombination of silane ions, producing a considerable amount of very reactive radicals, such as $\mathrm{SiH}_{2}, \mathrm{SiH}$, and $\mathrm{Si}$. The contribution of these radicals and/or their reaction products is expected to cause the inferior $a$-Si:H film properties obtained at low- $\mathrm{H}_{2}$ flows. This is corroborated by the decrease in overall surface reaction probability for increasing $\mathrm{H}_{2}$ flow, while the overall surface reaction probability of $\sim 0.3$ at high- $\mathrm{H}_{2}$ flows corresponds to film growth dominated by $\mathrm{SiH}_{3}$.

For a fixed $\mathrm{H}_{2}$ flow of $10 \mathrm{sccs}$ in the cascaded arc, the consumption of $\mathrm{SiH}_{4}$ has been investigated for varying $\mathrm{SiH}_{4}$ flows. That $\mathrm{SiH}_{3}$-dominated film growth does not guarantee good film quality is shown from the fact that the contribution of $\mathrm{SiH}_{3}$ is independent of the $\mathrm{SiH}_{4}$ flow, while the film properties are inferior at low- $\mathrm{SiH}_{4}$ flows. Furthermore, it has been demonstrated that the neutral products created by dissociative recombination of positive ions are smaller at low- $\mathrm{SiH}_{4}$ flows, as expected from the smaller size of the ions at these flows. 


\section{ACKNOWLEDGMENTS}

G. Dinescu and E. Aldea of the National Institute of Lasers and Plasma Physics, Romania, are gratefully acknowledged for providing the program for simulating the emission data and their help on the analysis. A. H. M. Smets, B. A. Korevaar, F. H. M. Hammen, and I. Aarts are thanked for their contributions to the measurements, and M. J. F. van de Sande, A. B. M. Hüsken, and H. M. M. de Jong for their skillful technical assistance. This work was supported by The Netherlands Organization for Scientific Research (NWOprioriteit), The Netherlands Foundation for Fundamental Research (FOM-Rolling Grant), and The Netherlands Agency for Energy and the Environment (NOVEM).

${ }^{1}$ K. Kobayashi, M. Hayama, S. Kawamoto, and H. Miki, Jpn. J. Appl. Phys., Part 1 26, 202 (1987).

${ }^{2}$ J. Perrin, P. Roca i Cabarrocas, B. Allain, and J. M. Friedt, Jpn. J. Appl. Phys., Part 1 88, 2041 (1988).

${ }^{3}$ A. H. Mahan, J. Carapella, B. P. Nelson, R. S. Crandall, and I. Balberg, J. Appl. Phys. 69, 6728 (1991).

${ }^{4}$ J.-H. Lee, S. K. Park, and C. S. Kim, Jpn. J. Appl. Phys., Part 2 34, L1191 (1995).

${ }^{5}$ M. Goto, H. Toyoda, M. Kitagawa, T. Hirao, and H. Sugai, Jpn. J. Appl. Phys., Part 1 36, 3714 (1997).

${ }^{6}$ S. Will, H. Mell, M. Poschenrieder, and W. Fuhs, J. Non-Cryst. Solids 227-230, 29 (1998).

${ }^{7}$ A. Heya, K. Nakata, A. Izumi, and H. Matsumura, Mater. Res. Soc. Symp. Proc. 507, 435 (1998).

${ }^{8}$ S. Morrison, J. Xi, and A. Madan, Mater. Res. Soc. Symp. Proc. 507, 559 (1998)

${ }^{9}$ R. Platz, C. Hof, S. Wieder, B. Rech, D. Fisher, A. Shah, A. Payne, and S. Wagner, Mater. Res. Soc. Symp. Proc. 507, 565 (1998).

${ }^{10}$ Y.-B. Park, X. Li, S.-W. Rhee, and D.-W. Park, J. Phys. D 32, 1955 (1999).

${ }^{11}$ W. M. M. Kessels, A. H. M. Smets, B. A. Korevaar, G. J. Adriaenssens, M. C. M. van de Sanden, and D. C. Schram, Mater. Res. Soc. Symp. Proc. 557, 25 (1999).

${ }^{12}$ B. A. Korevaar, G. J. Adriaenssens, A. H. M. Smets, W. M. M. Kessels, H.-Z. Song, M. C. M. van de Sanden, and D. C. Schram, J. Non-Cryst. Solids 266-269, 380 (2000).

${ }^{13}$ M. C. M. van de Sanden, R. J. Severens, W. M. M. Kessels, R. F. G. Meulenbroeks, and D. C. Schram, J. Appl. Phys. 84, 2426 (1998); 85, 1243 (1999).

${ }^{14}$ W. M. M. Kessels, R. J. Severens, A. H. M. Smets, B. A. Korevaar, M. C. M. van de Sanden, and D. C. Schram (unpublished).

${ }^{15}$ W. M. M. Kessels, C. M. Leewis, A. Leroux, M. C. M. van de Sanden, and D. C. Schram, J. Vac. Sci. Technol. A 17, 1531 (1999).

${ }^{16}$ W. M. M. Kessels, C. M. Leewis, M. C. M. van de Sanden, and D. C. Schram, J. Appl. Phys. 86, 4029 (1999).

${ }^{17}$ J. J. Beulens, M. J. de Graaf, and D. C. Schram, Plasma Sources Sci. Technol. 2, 180 (1993).

${ }^{18}$ M. C. M. van de Sanden, J. M. de Regt, and D. C. Schram, Plasma Sources Sci. Technol. 3, 501 (1994).

${ }^{19}$ R. F. G. Meulenbroeks, M. F. M. Steenbakkers, Z. Qing, M. C. M. van de Sanden, and D. C. Schram, Phys. Rev. E 49, 2272 (1994).

${ }^{20}$ R. F. G. Meulenbroeks, R. A. H. Engeln, M. N. A. Beurskens, R. M. J.
Paffen, M. C. M. van de Sanden, J. A. M. van de Mullen, and D. C. Schram, Plasma Sources Sci. Technol. 4, 74 (1995).

${ }^{21}$ M. Boulos, P. Fauchais, and E. Pfender, Thermal Plasmas: Fundamentals and Applications (Plenum, New York, 1994), Vol. 1.

${ }^{22}$ S. Mazouffre, M. G. H. Boogaarts, J. A. M. van der Mullen, and D. C. Schram, Phys. Rev. Lett. 84, 2622 (2000).

${ }^{23}$ G. M. W. Kroesen, D. C. Schram, A. T. M. Wilbers, and G. J. Meeusen, Contrib. Plasma Phys. 31, 27 (1991).

${ }^{24}$ R. F. G. Meulenbroeks, R. A. H. Engeln, J. A. M. van der Mullen, and D. C. Schram, Phys. Rev. E 53, 5207 (1996).

${ }^{25}$ H. Sugai and H. Toyoda, J. Vac. Sci. Technol. A 10, 1193 (1992).

${ }^{26}$ P. Kae-Nune, J. Perrin, J. Guillon, and J. Jolly, Plasma Sources Sci. Technol. 4, 250 (1995).

${ }^{27}$ Consumption of $\mathrm{SiH}_{4}$ usually leads to a decrease of the $\mathrm{SiH}_{4}$ signal when the plasma is turned on. This is, however, not the case for all measurements reported here. This effect, which cannot be explained by a change in $\mathrm{SiH}_{4}$ flux into the mass spectrometer due to a change in gas temperature, has no implications for the radical measurements.

${ }^{28}$ W. M. M. Kessels, M. C. M. van de Sanden, R. J. Severens, and D. C. Schram, J. Appl. Phys. 87, 3313 (2000).

${ }^{29}$ J. W. Coburn and E. Kay, J. Vac. Sci. Technol. 8, 738 (1971).

${ }^{30}$ H. Singh, J. W. Coburn, and D. B. Graves, J. Vac. Sci. Technol. A 17, 2447 (1999).

${ }^{31}$ A. J. B. Robertson, Mass Spectrometry (Methuen, London, U.K., 1954).

${ }^{32}$ G. J. Meeusen, E. A. Ershov-Pavlov, R. F. G. Meulenbroeks, M. C. M. van de Sanden, and D. C. Schram, J. Appl. Phys. 71, 4156 (1992).

${ }^{33}$ J. Perrin and E. Delafosse, J. Phys. D 13, 759 (1980).

${ }^{34}$ D. A. Doughty, J. R. Doyle, G. H. Lin, and A. Gallagher, J. Appl. Phys. 67, 6220 (1990).

${ }^{35}$ A. Goumri, W.-J. Yuan, L. Ding, Y. Shi, and P. Marshall, Chem. Phys. 177, 233 (1993).

${ }^{36}$ R. Basner, M. Schmidt, V. Tarnovsky, K. Becker, and H. Deutsch, Int. J. Mass Spectrom. Ion Processes 171, 83 (1997).

${ }^{37}$ V. Tarnovsky, H. Deutsch, and K. Becker, J. Chem. Phys. 105, 6315 (1996).

${ }^{38}$ F. A. Baiocchi, R. C. Wetzel, and R. S. Freund, Phys. Rev. Lett. 53, 771 (1984).

${ }^{39}$ This has consequences for the radical densities determined by Kae-Nune et al. and leads to a higher contribution of $\mathrm{SiH}_{3}$ to film growth than presented (the ratio of the contributions of $\mathrm{SiH}_{3}$ and $\mathrm{SiH}_{2}$ increases by a factor of $\sim 6$ ).

${ }^{40}$ J. Perrin, O. Leroy, and M. C. Bordage, Contrib. Plasma Phys. 36, 1 (1996).

${ }^{41}$ A. A. Howling, L. Sansonnens, J. L.-Dorrier, and Ch. Hollenstein, J. Appl. Phys. 75, 1340 (1994).

${ }^{42}$ S. Ramalingan, D. Maroudas, and E. S. Aydil (unpublished).

${ }^{43}$ Y. B. Kim, K. Stephan, E. Märk, and T. Märk, J. Chem. Phys. 74, 6771 (1981).

${ }^{44}$ A. A. Radzig and B. M. Smirnov, Reference Data on Atoms, Molecules and Ions (Springer, Berlin, 1985).

${ }^{45}$ S. K. Loh and J. M. Jasinski, J. Chem. Phys. 95, 4914 (1991).

${ }^{46}$ J. M. Jasinski, Mater. Res. Soc. Symp. Proc. 165, 41 (1990).

${ }^{47}$ A. Kono, S. Hirose, and T. Goto, Jpn. J. Appl. Phys., Part 1 38, 4389 (1999).

${ }^{48}$ A. H. M. Smets, M. C. M. van de Sanden, and D. C. Schram, Thin Solid Films 343-344, 281 (1999).

${ }^{49}$ S. Ramalingam, D. Maroudas, and E. S. Aydil, Appl. Phys. Lett. 72, 578 (1998); J. Appl. Phys. 84, 3895 (1998). 